\title{
Mc Cune Albright syndrome: estimation of bone strength parameters and response to treatment using peripheral Quantitive Computed Tomography (pQCT) of the tibia
}

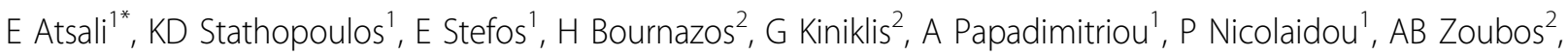 \\ G Skarantavos $^{2}$
}

From 18th Pediatric Rheumatology European Society (PReS) Congress

Bruges, Belgium. 14-18 September 2011

\section{Aim}

We assessed bone strength parameters and response to treatment in a girl with McCune -Albright syndrome (MAS) using tibia pQCT.

\section{Methods}

We present a $14 y$ old girl with polyostotic fibrous dysplasia (right humerus, femur, tibia, skull), precocious puberty and café au lait skin spots, diagnosed as MAS with a confirmed heterozygous c.601C $>\mathrm{T}$ mutation of the GNAS1 gene. Due to initial bone pain and continuously increasing bone turnover, the patient was treated with iv bisphosphonates for 4 years. We used pQCT to estimate bone strength parameters at the site of fibrous dysplasia lesion of the right tibia (38\% of tibia length) vs the same site of the left (healthy) tibia at baseline and after treatment. A Stratec XCT-2000 scanner was used (Stratec Medizintechnik, Pforzheim, Germany) and we specifically assessed for the $38 \%$ site cortical BMC (Cort_CNT), cortical BMD (Cort_DEN), cortical area (Cort_A), cortical thickness (Cort_THK) and Stress Strain Index (SSI) as an indicator of bending/torsional strength.

\section{Results}

At baseline all parameters were lower at the right (lesional) tibia: Cort_DEN (right 916.53 vs left 1154.47 $\left.\mathrm{mg} / \mathrm{cmA}^{3}\right)$, Cort_CNT (0.78 vs $\left.2.65 \mathrm{gr} / \mathrm{cm}\right)$, Cort_A (85 vs $230.25 \mathrm{~mm}^{2}$ ), Cort_THK ( 0.99 vs $4.76 \mathrm{~mm}$ ), SSI (941 vs $1110.35 \mathrm{~mm}^{3}$ ). All parameters increased significantly after 4 years of therapy at both legs with maximal increases at the lesional tibia: Cort_DEN (left $+10.16 \%$ vs right $+13.54 \%)$, Cort CNT $(+13.9 \%$ vs $+34.6 \%)$, Cort_A $(+3.14 \%$ vs $+19.7 \%)$, Cort_THK $(+4.2 \%$ vs $+19.19 \%)$, SSI $(+16.77 \%$ vs $+26.4 \%)$.

\section{Conclusions}

1) With 3- dimensional densitometry we can actually measure the loss of cortical bone and derived strength of lesional sites in MAS 2) All bone strength parameters improved with iv bisphosphonates. P QCT, where applicable, is an easy, safe and accurate method for non invasive monitoring of disease progress.

\section{Author details \\ ${ }^{1} 3^{\text {rd }}$ Pediatric Clinic, University of Athens, "Attikon" University Hospital, Greece. ${ }^{2}$ Bone Metabolic Unit, $1^{\text {st }}$ Orthopedic Clinic, University of Athens} ,"Attikon" University Hospital, Greece.

Published: 14 September 2011

doi:10.1186/1546-0096-9-S1-P27

Cite this article as: Atsali et al:: Mc Cune Albright syndrome: estimation of bone strength parameters and response to treatment using peripheral Quantitive Computed Tomography (pQCT) of the tibia. Pediatric Rheumatology 2011 9(Suppl 1):P27.

\footnotetext{
* Correspondence: eriatsali2000@yahoo.gr

${ }^{1} 3^{\text {rd }}$ Pediatric Clinic, University of Athens, "Attikon" University Hospital,

Greece

Full list of author information is available at the end of the article
}

(c) 2011 Atsali et al; licensee BioMed Central Ltd. This is an open access article distributed under the terms of the Creative Commons 